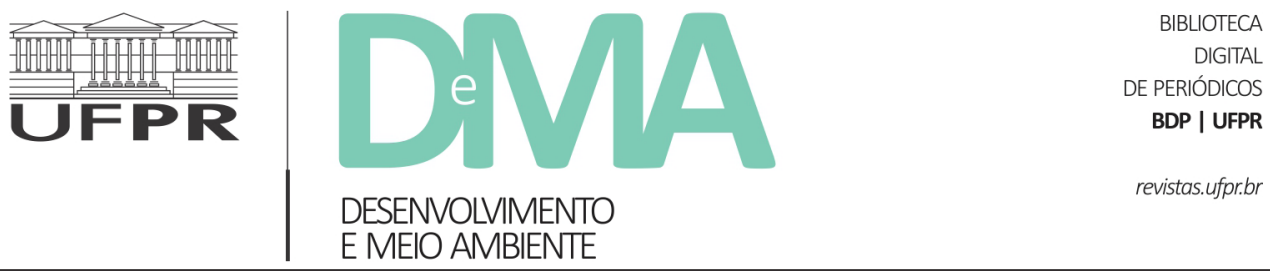

\title{
Potencial de oleaginosas nativas no desenvolvimento de cadeias produtivas da biodiversidade brasileira
}

\section{Native oilseeds as a potential of development by Brazilian biodiversity value chains}

\author{
Oscar Zalla SAMPAIO NETO ${ }^{*}$, Eduardo Augusto Caldas BATISTA², Antônio José de Almeida MEIRELLES ${ }^{2}$ \\ ${ }^{1}$ Universidade Federal do Mato Grosso (UFMT), Cuiabá, MT, Brasil. \\ ${ }^{2}$ Universidade Estadual de Campinas (UNICAMP), Campinas, SP, Brasil. \\ *E-mail de contato: oscarsampaio@ufmt.br
}

Artigo recebido em 26 de fevereiro de 2020, versão final aceita em 19 de agosto de 2020, publicado em 22 de dezembro de 2020.

RESUMO: $\quad$ Este artigo analisa e avalia os óleos da biodiversidade brasileira como potenciais indutores para o desenvolvimento de uma nova cadeia produtiva baseada nos produtos florestais não madeireiros e sua contribuição na transição para a bioeconomia. Primeiramente, o trabalho analisa dois modelos diferentes de produção, processamento e mercado de óleos vegetais, sendo um deles, o azeite de oliva na Comunidade Europeia. Este modelo indica caminhos para o aprimoramento da cadeia de valor dos óleos da biodiversidade brasileira. Em seguida, analisa-se o estado da arte do mercado brasileiro de óleos da biodiversidade e das políticas públicas de apoio à cadeia produtiva da sociobiodiversidade. Além disso, são descritas as características mercadológicas e tecnológicas das principais matérias-primas para a produção de óleos de produtos florestais não madeireiros, com destaque para os óleos da castanha-do-brasil e do babaçu. Os resultados indicam que esses óleos podem desempenhar um papel relevante para o aprimoramento da cadeia produtiva dos óleos da biodiversidade brasileira, porém identificou-se uma lacuna científica e tecnológica para o processo de extração e refino desses óleos vegetais. Esses avanços tecnológicos podem contribuir para a conservação dos biomas brasileiros, agregando valor aos produtos processados. Além dos desafios tecnológicos e de mercado para a produção de óleos da biodiversidade brasileira, a organização dessa cadeia de valor ainda exige um arcabouço institucional, legal, intersetorial e de confiança que estimule os atores a superar as atuais dificuldades da atividade extrativista. Como exemplo de quadro intersetorial, as indústrias brasileiras de higiene pessoal e farmacêutica, que conseguem uma diferenciação de mercado pela utilização de ativos vegetais como os óleos, extratos e/ou tinturas, demandam altos investimentos em PD\&I e, pelas características brasileiras, ganha relevância as parcerias e alianças entre empresas, universidades e institutos de pesquisa, e pequenas empresas locais. Concluindo, o trabalho recomenda arranjos sócio produtivos que integrem cooperativas e associações de comunidades locais, universidades e institutos 
de pesquisa, indústrias e instituições governamentais, a fim de tornar a biodiversidade brasileira um eixo estratégico para o desenvolvimento sustentável. No nível local, esse arranjo social poderia promover unidades descentralizadas de processamento de óleos vegetais e um rótulo ecológico específico para os produtos da sociobiodiversidade brasileira.

Palavras-chave: recursos florestais não madeireiros; sociobiodiversidade; sustentabilidade; óleos vegetais; desenvolvimento científico e tecnológico.

ABSTRACT: This paper analyze and evaluate Brazilian biodiversity oils as potential triggers for the development of a new value chain of no-timber forest products that will contribute for a transition to bioeconomy. Firstly the paper analyzes the production, processing, and market models of two different vegetable oils. The model based on the olive oil in EU indicates paths for the improvement for Brazilian biodiversity oils value chain. Then, state of art of Brazilian biodiversity oils market and public policies that supports the socio-biodiversity production chain is analyzed. In addition to that, market and technological characteristics of the main raw materials for the production of oils from no-timber forest products are described with emphasis in Brazil nuts and babassu oils. The results indicate that those oils can play a relevant role for the improvement of no-timber forest products value chain, however they have identified a gap of scientific and technological for vegetable oil extraction and refining process. These technological progresses contribute for the Brazilian biomes conservation by adding value in processed products. Beyond the technological and market challenges of Brazilian biodiversity oils production, the value chain still demands institutional, legal, cross-sectorial and trusting framework that encourage actors to overcome the present difficulties of extractive activities. As an example of a cross-sectorial framework, it is possible to mention the personal hygiene and pharmaceutical Brazilian industries. These industries develop a market differentiation by vegetable assets as Brazilian biodiversity oils, extracts and tinctures. For this development demand high investments in RD\&I. For the Brazilian characteristics, the partnerships and alliances between companies, universities or research institutes and small local enterprises become relevant. In conclusion, the paper recommend social productive arrangements that integrate cooperatives and associations of local communities, universities and research institutes, industries and government institutions in order to make Brazilian biodiversity a strategic axis for sustainable development. At the local level, this social arrangement could promote decentralized vegetable oil processing units and a specific Ecolabel for the products of the Brazilian socio-biodiversity.

Keywords: non-timber forest resources; sociobiodiversity; sustainability; vegetable oils; scientific and technological development

\section{Introdução}

Os óleos e gorduras de fonte animal ou vegetal têm tido importância crescente nos mercados mundiais. Inicialmente reconhecidos apenas como ótimas fontes calóricas na nutrição humana ou fonte energética para lamparinas, a identificação de ácidos graxos essenciais, além de diversos componentes minoritários que apresentam diferentes funções metabólicas (Gunstone \& Harwood, 2007), ampliaram as possibilidade de uso e colocaram os óleos vegetais como matéria-prima essencial para a indústria de cosméticos, particularmente, para a indústria brasileira, que consegue diferenciação no mercado com a utilização de óleos vegetais da biodiversidade local. Para além de suas qualidades como alimento, os óleos vegetais são promotores de diversos benefícios relacionados à nutrição da pele e dos cabelos, por apresentar propriedades umectantes, emolientes e lubrificantes, com baixo 
risco alergênico. Novas possibilidades de utilização dos óleos vegetais vêm sendo impulsionadas, como consequência do aquecimento global, na busca de alternativas para a substituição de produtos de origem fóssil, tendo como maior exemplo o desenvolvimento de combustíveis como o biodiesel, ou ainda, como lubrificantes de motores, máquinas e equipamentos.

Os óleos vegetais refinados têm características tradicionalmente encontradas como a cor clara, o sabor suave e a boa estabilidade oxidativa. Porém, a mudança do hábito alimentar, trazida pelo maior conhecimento das propriedades biológicas de componentes que estão naturalmente presentes nos óleos vegetais em seu estado bruto, abre novas possibilidades de processamento, devido à presença de tocóis, carotenoides, fitoesteróis, esqualeno, entre outros (Sampaio, 2011).

Apesar de ter processos consolidados, a indústria de óleos vegetais não está estática e tem procurado atender à demanda por processos ambientalmente mais limpos e produtos mais saudáveis (Kumar et al., 2017).

Neste cenário, e por todas essas caraterísticas, a produção e comercialização de óleos vegetais vêm tendo um forte impulso. Para a safra 2019/2020, existe a previsão de uma produção mundial de 205,49 milhões de toneladas, que representa um aumento de 17,5\% com relação à safra 2014/2015, com uma taxa de crescimento média anual próxima a 2,7\%. Neste mercado mundial, o Brasil se destaca como sétimo maior produtor e o sexto em consumo (USDA, 2020).

Com a identificação da necessidade de um desenvolvimento científico e tecnológico específico e da organização de um arranjo produtivo, institucional e legal, este artigo tem o objetivo de apresentar as potencialidades que os óleos vegetais da biodiversidade brasileira podem desempenhar como indutores de sustentabilidade social, ambiental e econômica. Com esse objetivo, este artigo se estrutura em seções que primeiro analisam e comparam dois modelos organizacionais e mercadológicos consolidados de óleos vegetais, seguindo pela indicação e exemplificação de novas oportunidades de agregação de valor aos produtos da sociobiodiversidade. Nas duas seções seguintes, são apresentados e analisados dados secundários sobre o mercado de óleos da biodiversidade e o arcabouço legal de políticas públicas de apoio a cadeia produtiva da sociobiodiversidade. Nas seções 5 e 6 são apresentadas as características mercadológicas e tecnológicas das principais matérias-primas para produção de óleos da biodiversidade. A penúltima seção amplia o olhar para as oportunidades e desafios para a construção da cadeia produtiva da sociobiodiversidade brasileira, sendo complementada com a última seção, que apresenta proposições para o seu desenvolvimento.

\section{Os modelos "soja/Brasil" e "azeite de oliva/UE"}

A apresentação dos modelos abrangendo a forma de organização produtiva, mercadológica e de comercialização do óleo de soja no Brasil e do azeite de oliva na Comunidade Europeia (UE) tem como objetivo identificar características que possam subsidiar a construção de um novo modelo para os óleos da biodiversidade brasileira, considerando suas especificidades tecnológicas, sociais e ambientais. 
Harwood \& Aparicio (2000) analisaram o mercado mundial de óleos vegetais e apontaram para o fato de o azeite de oliva representar menos de $2 \%$ do volume produzido, porém $15 \%$ dos recursos financeiros envolvidos, enquanto o óleo de soja representava $20 \%$ e $22 \%$, respectivamente. $\mathrm{Na}$ análise de Zampounis (2006), esse posicionamento mercadológico deve-se principalmente a ações do Internacional Olive Council - IOC, iniciadas nos anos 1990 e financiadas pela Comunidade Europeia, que promoveu grandes campanhas de divulgação, destacando o alto valor nutricional do azeite de oliva, resultando em um significativo aumento do consumo mundial e, principalmente, recolocando-o estrategicamente em uma nova categoria, de azeite de oliva extravirgem, desgarrando-se dos outros óleos vegetais na sua relação de valor.

$\mathrm{O}$ azeite de oliva não é uma commodity com preços fixados internacionalmente, como o óleo de soja, óleo de palma ou de girassol. Sendo o maior produtor e consumidor mundial, a UE estabeleceu um conjunto de medidas de política de coesão, que são: subsídio fixo ao produtor, independentemente de sua produção anual; incentivo ao consumo do azeite de oliva, frente aos outros óleos vegetais, e proteção aos produtores europeus da importação a preços baixos de países não pertencentes à $\mathrm{EU}$ (Zampounis, 2006). Duas características importantes que diferenciam o azeite de oliva no mercado mundial de óleos vegetais são: i) existência de uma organização internacional, a Internacional Olive Council - IOC; ii) a sua forma de produção e processamento.

Quanto ao IOC, esta organização tem como objetivos incentivar a cooperação técnica internacional em projetos de pesquisa e desenvolvimento, incentivar a expansão do comércio internacional de azeite e azeitonas de mesa, a elaboração e atualização de normas de comércio de produtos e melhoria da qualidade; reforçar o impacto ambiental da cultura da oliveira e da indústria de azeite; promover o consumo mundial de azeite e azeitonas de mesa, através de campanhas inovadoras e planos de ação; fornecer informações e estatísticas sobre o mercado de azeitona e do azeite de oliva; ativar representantes do governo e especialistas para reunir-se regularmente para discutir problemas e preocupações e fixar prioridades para a ação do IOC (IOC, 2016).

No Brasil, essa estratégia se reflete em suas instituições reguladoras. A Agência Nacional de Vigilância Sanitária - ANVISA, através da resolução RDC $n^{\circ} 270$ (ANVISA, 2005), define o azeite de oliva e suas variantes seguindo as diretrizes internacionais. Esta resolução define também os requisitos específicos de qualidade diferenciando os azeites de oliva extravirgem, virgem, azeite de oliva refinado e óleo de bagaço de oliva cru e refinado seguindo os requisitos estabelecidos nas normas do Codex Alimentarius - FAO/OMS (ANVISA, 2005). No Ministério da Agricultura, Pecuária e Abastecimento (MAPA), através de instrução normativa (MAPA, 2012), estabeleceu o regulamento técnico do azeite de oliva e do óleo de bagaço de oliva, definindo os padrões oficiais de classificação, com o azeite de oliva extravirgem definido como aquele obtido apenas por processos físicos, isto é, prensagem ou centrifugação, enquanto o óleo de bagaço de oliva é obtido da torta residual do processo físico, obtido por extração com solvente (hexano).

Já no cenário brasileiro, o óleo de soja possui importância significativa, mesmo sendo um coproduto da cadeia produtiva da soja. O Brasil é o quarto maior produtor mundial de óleo de soja, o segundo em exportações e o terceiro em consumo (USDA, 
2016). O óleo de soja é uma commodity com preços fixados internacionalmente, situação oposta ao azeite de oliva. Outra importante diferença se dá na sua forma de produção, pois enquanto o azeite de oliva prioriza a produção em sua forma bruta, obtido por método físico e não refinado, o óleo de soja é majoritariamente obtido pela extração com solvente (hexano) e comercializado na sua forma refinada. Com o atual aumento da demanda de óleo de soja para produção de biodiesel, a procura por óleo de soja bruto ou demogado tem aumentado proporcionalmente essa demanda.

Outro aspecto importante a ser comparado é a constituição da cadeia produtiva desses óleos vegetais. Para o óleo de soja, especificamente no Brasil, o setor industrial conta com 63 empresas e 121 plantas de processamento de oleaginosas para produção de óleos vegetais, com capacidade total instalada de 192.644 ton/dia. Para o refino de óleos vegetais, são 32 empresas com 58 plantas industriais com uma capacidade de 22.594 ton/dia (ABIOVE, 2018). Em 2018, o Brasil produziu aproximadamente 8,9 milhões de toneladas de óleo de soja. Os dados consolidados do Censo Agropecuário de 2006 apontam que no setor agrícola para produção de soja eram 215.977 estabelecimentos, sendo 11.037 com área acima de 500 ha, que representavam $5,1 \%$ do total de estabelecimentos, respondendo por $58,7 \%$ da área colhida (IBGE, 2009). O Censo Agropecuário de 2017 aponta que o número de estabelecimentos saltou para 236.245, porém ainda não foram disponibilizados dados referentes ao tamanho das propriedades.

Para o azeite de oliva, tendo a Espanha como referência devido à importância econômica dessa cadeia produtiva, existiam 1.816 moinhos para extração do azeite de oliva, responsáveis pela produ- ção de aproximadamente 1,3 milhões de toneladas na safra 2016/2017 (AICA, 2017). As propriedades rurais com área útil inferior a 5 ha representavam $51 \%$ do total de propriedades, concentrando $17 \%$ da área total cultivada, e as propriedades com área superior a 50 ha representavam $6 \%$ das propriedades e $36 \%$ da área total de cultivo (Navarro, 2000b). A cadeia de produção de azeite de oliva na Espanha tem como agentes econômicos centrais as cooperativas de diferentes graus, nas quais os proprietários são os próprios produtores rurais, representando em torno de $55 \%$ das moendas e de $70 \%$ da produção agrícola (Navarro, 2000a). A autora destaca que uma das grandes revoluções ocorridas na cadeia de produção do azeite de oliva foi a entrada das moendas na atividade de envase que, somada ao aumento do consumo, potencializou a instalação massiva de pequenas envasadoras.

Dos dois modelos de organização produtiva e das características mercadológicas de produção e comercialização, o modelo desenvolvido na UE para a cadeia produtiva do azeite de oliva é inspirador para o desenvolvimento do arranjo produtivo dos óleos da biodiversidade, fato este entendido não como cópia tampouco como reprodução, mas sim como insumo para o desenvolvimento de um novo modelo econômico com sustentabilidade social, ambiental e de geração de renda. Corrobora essa opção o trabalho de Vosti et al. (2003), que simularam e analisaram os resultados financeiros de propriedades de pequena escala na Amazônia Ocidental brasileira. Os autores sugerem que a gestão, extração e comercialização de produtos da floresta de forma sustentável terão maior rentabilidade para os agricultores/extrativistas que trabalhem em conjunto, de forma cooperativa. 
Indo além das características de produção e comercialização e considerando as especificidades brasileiras e suas características socioambientais, Escobal \& Aldana (2003) analisaram a relação entre pobreza e degradação florestal e a influência da exploração econômica dos recursos florestais não madeireiros como antídoto para a redução do desmatamento. Os autores concluíram que a sazonalidade de atividades, tendo como exemplo o extrativismo da coleta de castanha-do-brasil, não possibilita a redução do desmatamento quando são seguidas de atividades silvícolas. Os autores apontam que apenas as pessoas de baixa renda, que conseguem atividades em outro setor, conseguem romper essa relação. Nesse sentido, deve-se pensar em unidades produtivas multiprocessadoras, que possibilitem o beneficiamento de produtos florestais não madeireiros com diferentes sazonalidades. Esta é justamente uma das principais características que podem ser desenvolvidas nas unidades processadoras de óleos da biodiversidade, já que existe uma gama de sementes oleaginosas e de frutos, tais como castanha-do-brasil, babaçu, buriti, andiroba, pequi, cumbaru, entre muitos outros, com diferentes épocas de coleta e que podem ser submetidos a um mesmo processo de extração e beneficiamento.

Neste modelo, as ideias defendidas por Shiki (2010), de pagamentos por serviços ambientais, podem ser agregadas, auxiliando na sustentabilidade econômica dos empreendimentos envolvidos. Como exemplo de arranjo organizacional que já procura desenvolver esse novo modelo, Davenport et al. (2016) pesquisaram o arranjo local de agregação de valor no processamento da castanha-do-brasil desenvolvido pela Cooperativa dos Agricultores do Vale do Amanhecer (COOPAVAM) e pela Associação de Mulheres Cantinho da Amazônia (AMCA), na região noroeste do estado de Mato Grosso. Baseadas em um arranjo de entidades e projetos de apoio e com o bom uso de políticas públicas, estas duas organizações criaram condições estruturais que incluem uma infraestrutura para coleta e processamento da castanha-do-brasil, assistência técnica e suporte financeiro apropriados. Nos aspectos ambientais, destaca-se a legalização do uso sustentável da terra e a certificação do manejo florestal. Apenas com os programas federais de compras públicas, essas organizações movimentaram valores ao redor de quatro milhões de reais em três anos, beneficiando 40.000 pessoas. Os principais produtos de comercialização são a castanha sem casca, o óleo e produtos de panificação, tais como macarrão e biscoitos produzidos com a farinha semidesengordurada. $\mathrm{O}$ óleo é o produto de maior valor agregado, sendo comercializado por valores até sete vezes superior ao da farinha semidesengordurada. O óleo produzido pela COOPAVAM tem como principal cliente uma grande indústria brasileira de cosméticos.

A COOPAVAM utiliza o processo de prensagem para a extração de óleo de castanha-do-brasil. A farinha semidesengordurada, que é a torta do processo de prensagem e, portanto, um coproduto da produção de óleo de castanha-do-brasil, é obtida com teores de óleo em torno de 50\% (Sampaio Neto et al., 2018), fato que abre a possibilidade para a aplicação e desenvolvimento de tecnologias que aumentem o rendimento do processo de extração de óleo.

\section{O mercado dos óleos da biodiversidade brasileira}

A maior demanda pelos óleos da biodiversidade brasileira vem da indústria de cosméticos. 
A Associação Brasileira de Indústrias de Higiene Pessoal, Perfumaria e Cosméticos - ABIHPEC, analisa periodicamente o panorama do setor, em que se destaca o crescimento médio anual deflacionado composto de $4,5 \%$ nos últimos 10 anos, bem acima do crescimento médio anual deflacionado composto do PIB total do país ou mesmo do decrescimento da indústria em geral, 1,6 e - $0,6 \%$ no mesmo período. Após mais de uma década de superávit na balança comercial, a partir de 2011, o setor vem apresentado déficit comercial, tendo atingido o ápice em 2013 em 412 milhões de dólares. Dos 153 países que são destinos das exportações brasileiras, o principal mercado é o latino-americano. Existem 2.650 empresas registradas na ANVISA que atuam no mercado de produtos de higiene pessoal, perfumaria e cosméticos, sendo que 20 empresas são de grande porte e representam $75 \%$ do faturamento total. No mercado mundial, o Brasil ocupa a quarta posição, com faturamento de 29,3 bilhões de dólares, representado $6,6 \%$ do consumo mundial (ABIHPEC, 2019).

Dados do Ministério do Meio Ambiente (MMA) evidenciam o desenvolvimento industrial com a utilização dos óleos da biodiversidade. Um estudo realizado pelo Ministério em 2006 (MMA, 2006) localizou dez empresas que compravam ou fabricavam produtos à base de óleos vegetais, resinas ou manteigas das seguintes espécies da Região Amazônica: açaí, andiroba, babaçu, breu branco, buriti, castanha-do-brasil, copaíba, cupuaçu, murumuru, patauá, priprioca e ucuúba. As espécies mais utilizadas (sem considerar o volume) pelas empresas pesquisadas eram nesta ordem: castanha-do-brasil, andiroba, cupuaçu, buriti e murumuru. A maior parte da variedade de óleos produzida é voltada para a indústria de cosméticos, perfumaria e higiene pes- soal. Isso se deve, em parte, ao fato de grande parte das empresas localizadas pelo estudo pertencerem a esse setor. Já o óleo de babaçu tem como maior produtor o estado do Maranhão, que responde por mais de $90 \%$ da produção nacional de amêndoas de babaçu. Já no ano de 2016, em seu banco de dados, o Ministério do Meio Ambiente (MMA, 2016), considerando apenas as indústrias químicas, alimentícias, de cosméticos e higiene pessoal que utilizam a castanha-do-brasil e o babaçu como matéria-prima, tinham cadastradas 152 empresas. Apesar de não ser adequada uma comparação direta entre os dados no intervalo de dez anos, pois tratam-se de amostragens diferentes, pode-se induzir o forte potencial de crescimento existente no setor.

Outro mercado de destaque é o de compras públicas. Os principais mecanismos de aquisição são o Programa de Aquisição de Alimentos - PAA e o Programa Nacional de Alimentação Escolar PNAE, acompanhados pela Política de Garantia de Preço Mínimo dos Produtos da Sociobiodiversidade - PGPM-Bio. O PAA (Brasil, 2003; 2012a) possibilita ao governo federal brasileiro a compra, com dispensa de licitação, de alimentos diretamente produzidos por assentados da reforma agrária, comunidades indígenas e demais povos e comunidades tradicionais da agricultura familiar, para constituição de estoques estratégicos ou destinando às pessoas em situação de insegurança alimentar $\mathrm{e}$ nutricional. O PNAE (Brasil, 2009) prevê o uso de no mínimo $30 \%$ de seus recursos para a aquisição de produtos da agricultura familiar com dispensa de processos licitatórios. A PGPM-Bio (Brasil, 1966; Brasil, 2008) permitiu a modalidade de Subvenção Direta, com garantia de um preço mínimo para mais de 15 produtos extrativistas que ajudam na conservação do meio ambiente. Dentre esses, des- 
tacam-se o açaí, andiroba, babaçu, baru, borracha extrativa, cacau extrativo, castanha-do-brasil, carnaúba, juçara, macaúba, mangaba, pequi, piaçava, pinhão e umbu. Estudos estão sendo elaborados, com o intuito de incluir novos produtos, tais como o buriti, o pirarucu de manejo e outros. Esse conjunto de políticas públicas se propõe a fomentar a proteção ao meio ambiente, contribuir com a redução do desmatamento, como forma de minimizar os efeitos das mudanças climáticas, garantindo, inclusive, renda às populações que possuem formas próprias de organização social, que ocupam e usam territórios e recursos naturais como condição para sua reprodução cultural, social, religiosa, ancestral e econômica, utilizando conhecimentos, inovações e práticas gerados e transmitidos pela tradição.

\section{Políticas públicas de apoio à organização da cadeia de produtos da sociobiodiversidade}

Há mais de três décadas, o Brasil vem construindo políticas públicas que objetivam criar condições favoráveis para o desenvolvimento da cadeia produtiva da sociobiodiversidade. A Política Nacional da Biodiversidade (Brasil, 2002) tem como base os compromissos assumidos pelo Brasil ao assinar a Convenção sobre a Diversidade Biológica, e carrega nos seus fundamentos e diretrizes a conservação e o uso sustentável da biodiversidade como elementos fundamentais para o desenvolvimento econômico e social e a erradicação da pobreza. Já o Programa Nacional de Fortalecimento da Agricultura Familiar - PRONAF (Brasil, 1996a) tem como finalidade o desenvolvimento sustentável do segmento rural da agricultura familiar e como estratégia as parcerias entre os governos municipais, estaduais e federal, a inciativa privada e os agricultores familiares e suas organizações. Nos últimos 20 anos, foram disponibilizados 156 bilhões de reais distribuídos para 5.379 municípios, com mais de 2,6 milhões de famílias atendidas. Para a safra 2015/2016, foram destinados 29,8 bilhões de reais. Em seu aperfeiçoamento foram criadas modalidades especiais de PRONAF, que atendem diretamente a cadeia produtiva da sociobiodiversidade, tais como o PRONAF Floresta, PRONAF Eco e o PRONAF Agroecologia. O PRONAF, em combinação com as políticas públicas de compras governamentais, cria uma rede de suporte financeiro da produção à comercialização.

O Plano Nacional de Promoção das Cadeias de Produtos da Sociobiodiversidade - PNPSB (MDA et al., 2009) tem por objetivo desenvolver ações integradas para a promoção e o fortalecimento das cadeias de produtos da sociobiodiversidade. $\mathrm{O}$ PNPSB está estruturado em eixos que visam apoiar a produção, estruturar os processos industriais, fortalecer as organizações sociais e produtivas e valorar os serviços da sociobiodiversidade. Em 2013 o PNPSB foi incorporado ao Plano Nacional de Agroecologia e Produção Orgânica - PLANAPO (CIAPO, 2013), e em 2016 foi criado um eixo específico para a sociobiodiversidade.

A cadeia de produtos da sociobiodiversidade é intrinsicamente ligada a políticas públicas ambientais e de preservação da identidade cultural das comunidades tradicionais. Nestes campos, o Brasil vem consolidando sua legislação, que é internacionalmente reconhecida como moderna, não deixando de ter suas lacunas e necessidades de aperfeiçoamento. Destaca-se o novo Código Florestal Brasileiro (Brasil, 2012b), que apesar de 
ter trazido uma redução nas áreas de conservação permanentes, entre outras alterações, reconhece a importância da preservação dos biomas brasileiros quando determina áreas mínimas de preservação da vegetação nativa, determinação esta que raramente está presente na legislação dos demais países. Outras importantes legislações são a Política Nacional para o Desenvolvimento Sustentável das Comunidades Tradicionais (Brasil, 2007) e a Lei de Acesso a Recursos Genéticos e Conhecimento Tradicional Associado e a Repartição dos Benefícios (Brasil, 2015).

Como resultado do papel de destaque nos debates globais sobre mudanças climáticas e desenvolvimento sustentável que o Brasil ocupou até 2018, foram desenvolvidas iniciativas globais encabeçadas por organismos internacionais que também repercutiram no desenvolvimento das políticas públicas brasileiras, que têm como tema a sociobiodiversidade. Um exemplo é a Iniciativa Valoração do Capital Natural do Brasil - Projeto TEEB Brasil, vinculada ao estudo global The Economics of Ecosystems \& Biodiversity, coordenado pelo Programa das Nações Unidas para o Meio Ambiente (PNUMA). O objetivo do TEEB é, a partir da valoração da biodiversidade e dos serviços ecossistêmicos e considerando toda a complexidade e reconhecendo os seus limites, criar conexões entre as práticas governamentais e o setor de negócios, a ciência multidisciplinar da biodiversidade e as políticas nacionais e internacionais (Sukhdev et al., 2010). No Brasil, este estudo foi coordenado pelo Ministério do Meio Ambiente - MMA, contando com parcerias e corresponsabilidades do Ministério da Fazenda, do Instituto de Pesquisa Econômica Aplicada - IPEA, do Programa das Nações Unidas para o Meio Ambiente - PNUMA, da Confedera- ção Nacional da Indústria - CNI e da Conservação Internacional do Brasil. Esse estudo visou identificar e ressaltar os benefícios econômicos oriundos da biodiversidade e serviços ecossistêmicos brasileiros, avaliando os custos crescentes de sua perda, bem como as oportunidades geradas pela sua conservação e uso sustentável. O relatório da fase I (Roma et al., 2012) analisou as lacunas para a continuidade do projeto, destacou a identificação de bom número de grupos de pesquisas e pesquisadores no Brasil atuantes na área, mas com uma produção científica de valoração dos serviços ecossistêmicos que não possibilita uma visão ampla do valor do capital natural brasileiro, além de apontar para a necessidade de considerável esforço na governança referente à gestão do conhecimento e das relações de diferentes atores.

\section{Características mercadológicas das principais matérias-primas dos óleos da biodiversidade brasileira}

\subsection{Castanha-do-brasil (Bertholletia excelsa)}

Conhecida popularmente no Brasil com o nome de castanha-do-pará, teve sua denominação definida como castanha-do-brasil, para efeito de comércio exterior, pelo decreto lei no 51.209 (Brasil, 1961). Dados referentes à produção e comercialização brasileira da castanha-do-brasil no período 2009 a 2017 são apresentados na Figura 1, em que se observa uma constância no volume produzido até 2015. Evidencia-se a valorização de produtos com agregação de valor, pois enquanto o preço da castanha sem casca teve o seu valor dobrado de 2009 
a 2016 e com um pico no ano de 2017, a castanha com casca apresenta uma tendência de manutenção do valor.

O conhecimento da capacidade de extração de castanha-do-brasil depende de levantamentos florísticos que forneçam esses dados, da mesma forma como outros produtos de fonte extrativista. Outro fator relevante é o entendimento do impacto que a coleta desses frutos pode desempenhar na manutenção da espécie e dos ecossistemas onde estão inseridas. Diversos estudos, dentre eles Wadt et al. (2005), Salomão (2009), Paiva et al. (2011), Tonini (2013), Tonini \& Pedrozo (2014), Thomas et al. (2017) e Wadt et al. (2018) avaliaram e quantificaram a abundância das castanheiras em matas nativas da Amazônia brasileira, sua produção, principais variáveis que influenciam na sua produção concomitantemente ao entendimento da ecologia dos castanhais indicando as melhores práticas para sua sustentabilidade, e uma gama de avaliações, considerações e perspectivas de diferentes aspectos que circundam a coleta extrativista considerando por um lado a conservação da espécie e do outro as populações que dela geram trabalho e renda. Vale ressaltar a importância de pesquisas que procuram entender a ecologia dos castanhais para o desenvolvimento das melhores práticas para sua sustentabilidade populacional e o possível aumento de sua produtividade (Wadt et al., 2005), potencializando os serviços ecossistêmicos prestados e a geração de trabalho e renda para os povos da floresta. De forma complementar, o trabalho realizado por Wadt et al. (2018) indica que a coleta extrativista pode ocorrer tendo impacto controlado sobre a reprodução da espécie se os dispersores naturais tiverem acesso ilimitado aos recursos.

Existe uma enorme variabilidade na produção de castanhas devido às características de cada árvore, tais como diâmetro, altura (DAP), forma da copa, presença de polinizadores, condições bióticas e abióticas, além de fatores não naturais resultantes da ação entrópica, entre outras. Todavia, o acúmulo de conhecimento sobre a sua estrutura populacional na Amazônia ainda é insuficiente. A Embrapa,

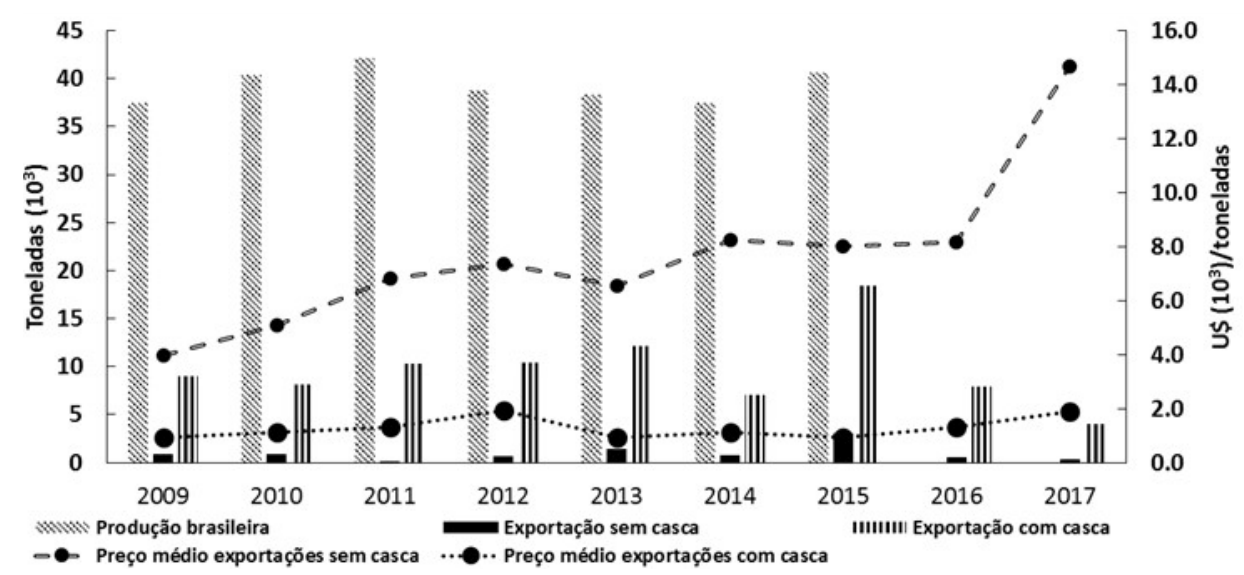

FIGURA 1 - Produção brasileira de castanha-do-brasil e mercado exterior

FONTE: IBGE (2017); MDIC (2018) 
através da Rede Kamukaia, realiza um grande monitoramento da produção de castanheiras em parcelas permanentes localizadas em quatro estados brasileiros (Acre, Amapá, Mato Grosso e Roraima). Os dados para o período de 2007 a 2017 indicam a grande variação anual de produção em cada uma das parcelas, caracterizando uma oscilação natural, porém destaca-se a significativa queda de produção em todas as parcelas no ano de 2017, fato que justifica a forte alta do preço médio das exportações da castanha sem casca apresentada na Figura 1.

Na busca de dados de maior precisão do potencial extrativista da castanha-do-brasil, a Empresa Brasileira de Pesquisa Agropecuária (Embrapa) executou o projeto intitulado "Mapeamento de Castanhais Nativos e Caracterização Socioambiental e Econômica de Sistema de Produção de castanha-do-brasil na Amazônia" (MapCast). Além de quantificar os castanhais, o projeto teve o objetivo de realizar a caracterização socioambiental e econômica de sistemas de produção da castanha-do-brasil, colhendo informações importantes, desde a produção até a comercialização do produto.

Com relação às qualidades como alimento, Yang (2009) realizou uma revisão que associa a castanha-do-brasil e os seus benefícios à saúde. $\mathrm{O}$ trabalho consolida as evidências relacionadas aos minerais e fitoquímicos presentes na castanha-do-brasil, assim como seus mecanismos e associações. $\mathrm{O}$ autor qualifica a castanha-do-brasil como boa fonte de nutrientes, sejam macronutrientes, como citado anteriormente, mas também com relação aos micronutrientes, com destaque para o selênio, sendo o alimento com valor mais elevado, e com os seus efeitos correspondentes de benefício à saúde.

\subsection{Babaçu (Orbignya phalerata ou Attalea speciosa)}

Carrazza et al. (2012), com o objetivo de promover a reaplicação de tecnologias sustentáveis, identificaram a cadeia produtiva do babaçu como uma das mais representativas do extrativismo vegetal no Brasil, devido a sua abrangência (13 a 18 milhões de hectares em 279 municípios, situados em 11 Estados), suas potencialidades econômicas, sua importância para famílias que sobrevivem da agricultura de subsistência e forte mobilização social e política em favor do acesso livre aos babaçuais. $\mathrm{O}$ maior produtor de óleo de babaçu do Brasil é estado do Maranhão. Na Figura 2, que apresenta dados da produção e comercialização brasileira de amêndoas de babaçu e de óleo de babaçu, observa-se uma constante diminuição no volume produzido, com uma redução média anual de 5,13\%, sendo que, para o último triênio, a tendência de redução se acentua. Na cadeia produtiva do babaçu, os produtos de exportação são o óleo bruto e os denominados outros óleos, que correspondem ao óleo bruto com certificação orgânica (MDIC, 2017). Na Tabela 1, observa-se forte crescimento no volume exportado dos óleos de babaçu no ano de 2009, seguido de uma tendência de estabilização no volume exportado do óleo bruto e de crescimento para o óleo certificado. Na mesma figura, ainda se observa uma constância no valor pago pela tonelada do óleo bruto, enquanto para o óleo certificado o valor pago por tonelada apresentou uma tendência de crescimento até 2014, uma queda e uma tendência de estabilização para o final do período. Assim como para a cadeia produtiva da castanha-do-brasil, evidencia-se a valorização de produtos com agregação de valor. 


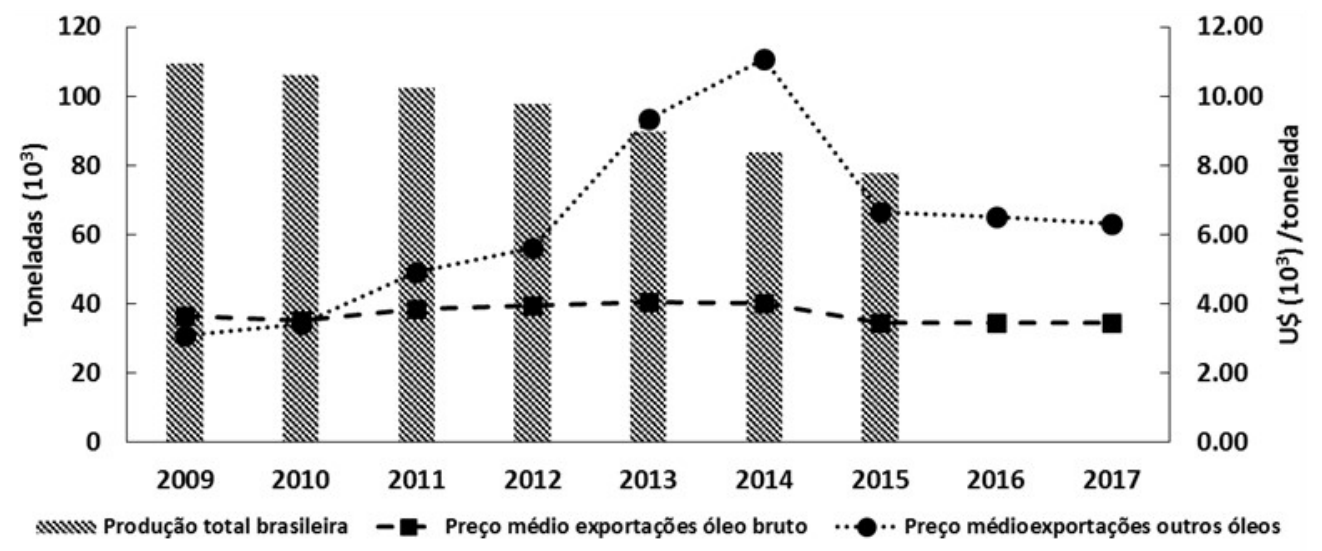

FIGURA 2 - Produção brasileira de babaçu e mercado exterior de óleo de babaçu.

FONTE: IBGE (2017) e MDIC (2018)

TABELA 1 - Quantidades exportadas de óleo de babaçu (ton.)

\begin{tabular}{lcccccccc}
\hline & $\mathbf{2 0 0 9}$ & $\mathbf{2 0 1 0}$ & $\mathbf{2 0 1 1}$ & $\mathbf{2 0 1 2}$ & $\mathbf{2 0 1 3}$ & $\mathbf{2 0 1 4}$ & $\mathbf{2 0 1 5}$ & $\mathbf{2 0 1 6}$ \\
\hline Óleo bruto & 63,72 & 100,84 & 115,63 & 72,10 & 100,81 & 129,61 & 101,00 & 101,48 \\
Óleo orgânico & 16,13 & 63,57 & 44,85 & 25,66 & 90,22 & 62,33 & 88,06 & 80,27 \\
\hline
\end{tabular}

FONTE: IBGE (2017) e MDIC (2018).

A palmeira de babaçu produz frutos, também chamados de cocos, dispostos em cachos. A composição dos frutos e suas respectivas participações estão apresentadas na Tabela 2, sendo estes constituídos de epicarpo, mesocarpo, endocarpo e castanha. O epicarpo é formado por fibras resistentes, já o mesocarpo contém de $20 \%$ a $25 \%$ de amido. $\mathrm{O}$ endocarpo, também rico em fibras e maior constituinte do fruto, é matéria-prima para a fabricação de isolantes térmicos e para a produção de álcool metílico, ácido acético, alcatrão e carvão. As castanhas encontram-se inseridas no interior do endocarpo e constituem aproximadamente $6 \%$ do fruto (Machado et al., 2006). Os autores observaram que o óleo de babaçu tem como principal destino as indústrias de higiene e limpeza.

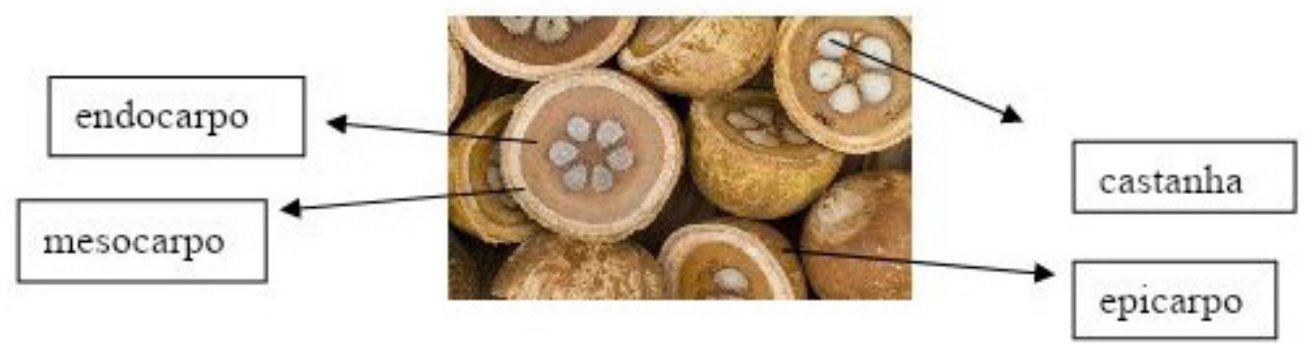

FIGURA 3 - Fruto do babaçu. 
TABELA 2 - Percentual das partes do fruto do babaçu.

\begin{tabular}{lc}
\hline Componente & Percentuais (\%) \\
\hline Epicarpo & 15 \\
Mesocarpo & 20 \\
Endocarpo & 59 \\
Castanha & 6 \\
\hline
\end{tabular}

FONTE: Pinheiro \& Frazao (1995).

\subsection{Outras oleaginosas}

Na classificação utilizada pelo IBGE, além do babaçu, incluem-se na categoria de oleaginosas o cumaru (amêndoa), licuri (coquilho), oiticica (semente), pequi (amêndoa), tucum (amêndoas), óleo resina de copaíba (Copaifera langsdorffii) e outras. A Tabela 3 apresenta os dados de extrativismo vegetal desses produtos para o período de 2009 a 2015.

Apesar da pequena representatividade em quantidade produzida, quando comparado aos principais produtos (babaçu e castanha-do-brasil), as oleaginosas demonstram a grande diversidade de produtos existentes para a produção dos óleos da biodiversidade brasileira, podendo-se destacar ainda o murumuru (Astrocaryum murumuru), an- diroba (Carapa guianensis), cupuaçu (Theobroma grandiflorum), patauá (Jessenia bataua), bacaba (Oenocarpus distichus), inajá (Maximiliana regia), tucumã (Astrocaryum tucuma), ouricuri (Syagrus coronata), ucuhuba (Virola surinamensis), açaí (Euterpe oleracea), pupunha (Bactris gasipaes), indaiá (Attalea funifera), oiticica (Licania rigida), macahuba (Acrocomia spp) e bacury (Platonia insignans).

\section{Extração de óleos vegetais: características e inovações tecnológicas}

A extração de óleos vegetais a partir de polpa de frutas, sementes ou farelos tem o domínio dos processos mecânicos de prensagem e físico por uso de solventes, ou a combinação destes. Independentemente do processo de extração, os objetivos são a obtenção de um óleo ou gordura que mantenha ao máximo as suas qualidades originais, seja nutricional ou tecnológico, tenha alta produtividade com resultados econômicos e a produção de um resíduo sólido (torta), de boa qualidade nutricional e tec-

TABELA 3 - Produção extrativista de outras oleaginosas da biodiversidade (toneladas).

\begin{tabular}{|c|c|c|c|c|c|c|c|}
\hline & 2009 & 2010 & 2011 & 2012 & 2013 & 2014 & 2015 \\
\hline Cumaru (amêndoa) & 97 & 95 & 103 & 93 & 91 & 103 & 97 \\
\hline Licuri (coquilho) & 4654 & 4307 & 4213 & 3925 & 3760 & 3744 & 4072 \\
\hline Oiticica (semente) & 250 & 37 & 64 & 401 & 15 & 16 & 12 \\
\hline Tucum (amêndoa) & 636 & 517 & 516 & 482 & 513 & 484 & 489 \\
\hline Outros & 184 & 514 & 443 & 395 & 333 & 632 & 674 \\
\hline
\end{tabular}

FONTE: IBGE (2017). 
nológica (Wakelyn et al., 2006). Historicamente, a etapa de extração era entendida como o coração do processo de obtenção de óleos vegetais (Karnofsky, 1949), posteriormente, procurou-se a otimização do processo de obtenção de óleos vegetais, considerando todas as etapas integradas com foco na qualidade e quantidade de seus produtos (Anderson, 1996).

Muito se discute sobre qual o melhor método a ser empregado para a extração de óleos vegetais (Wakelyn et al., 2006; Dijkstra \& Segers, 2007; Kumar et al., 2017), tendo como variáveis o tipo de solvente, o rendimento, a qualidade do óleo e do resíduo sólido e as necessidades de etapas de pré-tratamento da matéria-prima. Tal definição depende das características e objetivos específicos do empreendimento que realizará o processo.

\section{Olhando além: desafios, oportunidades $e$ exemplos}

O modelo extrativista que define a coleta da maior parte dos produtos florestais não madeireiros (PFNM) no Brasil é caracterizado por um grande esforço e custo de mão de obra e, dependendo da matéria-prima e da região de coleta, um baixo volume e um mercado escasso.

Além das dificuldades mercadológicas, Shanley et al. (2012) destacam a falta de dados estatísticos que quantificam a real produção e geração de renda oriunda do mercado de PFNM, fato que dificulta o desenvolvimento da cadeia produtiva e a criação de políticas públicas específicas, que resulta na marginalização desse mercado. Quando os extrativistas não estão organizados em cooperativas ou associações, eles têm que comercializar isoladamente sua produção, tendo na maioria das vezes como única opção intermediários, reduzindo as possibilidades de obtenção de melhores preços. São muitos os atores presentes nessa cadeia produtiva, de diferentes categorias e tamanhos, quais sejam: extrativistas, intermediários, cooperativas e associações, organizações não governamentais, organismos estatais dos três níveis de poder das esferas executiva e legislativa, indústrias produtoras e transformadoras, com destaque para as indústrias de grande e médio porte da área de cosméticos e higiene pessoal. A organização de toda essa cadeia, com a complexidade de interações existentes, demanda um arcabouço institucional, legal e de relações de confiança que incentive os atores a superar as dificuldades presentes pela própria natureza da atividade extrativista, que visa às sustentabilidades social, ambiental e econômica.

Como exemplo de ação que ainda não alcançou os resultados esperados, Saccaro Jr (2011) cita o Centro de Biotecnologia da Amazônia - CBA, em Manaus, no âmbito do Programa Brasileiro de Ecologia Molecular para o Uso Sustentável da Biodiversidade - PROBEM. O autor indica que a desvinculação entre iniciativas governamentais executadas por diferentes órgãos e, principalmente, a dificuldade de definição dos arranjos políticos e institucionais adequados, resultaram na subutilização de uma interessante estrutura de pesquisa. Alterar esse quadro é um desafio que envolve os ministérios do Meio Ambiente (MMA), do Desenvolvimento, Indústria, Comércio Exterior e Serviços (MDIC) e da Ciência, Tecnologia e Inovações e Comunicações (MCTIC), aos quais o CBA está vinculado, além dos demais atores da cadeia produtiva. Ainda no campo científico e tecnológico, a criação do Sistema de informação sobre a biodiversidade brasileira $-\mathrm{SiBBr}$ (MCTIC, 2017), plataforma online que pretende 
reunir a maior quantidade de dados e informações existentes sobre a biodiversidade do Brasil, possibilita um ambiente que favorece o cruzamento de dados de temas, como uso, conservação, saúde, monitoramento e coleções biológicas, o que facilita e articula ações intersetoriais e interdisciplinares.

Por outro lado, como exemplo de articulação intersetorial, tem-se o arranjo institucional capitaneado pelo Escritório de Inovação Tecnológica da Universidade Federal de Mato Grosso (EIT-UFMT), a sua incubadora (Incubadora Priante) e a Cooperativa dos Pescadores e Artesãos do Pai André e Bonsucesso (COORIMBATÁ). Em conjunto com outras organizações, desenvolve a tecnologia social "Sistema Integrado de Inovação Tecnológica e Social - SITECS” (Arakaki et al., 2012), que, por meio de diferentes projetos, pesquisas científicas e tecnológicas e programas de extensão universitária, desenvolve ações com foco na promoção de melhores condições de vida para a população e maior competitividade da economia regional. Para o desenvolvimento da cadeia produtiva da sociobiodiversidade no Território da Cidadania da Baixada Cuiabana, são desenvolvidas ações com a finalidade de gerar renda para as famílias agroextrativistas, ribeirinhos e dar sustentabilidade aos seus empreendimentos econômicos solidários. Com esse intuito, várias entidades articulam-se em rede, de forma a possibilitar que o trabalho extrativista dessas comunidades, de coleta e beneficiamento dos produtos da sociobiodiversidade, tenham garantia de comercialização. Os principais produtos de coleta e beneficiamento são o babaçu e o cumbaru, servindo como complemento das atividades familiares na sua busca de garantias de sobrevivência econômica e alcance de soberania alimentar nas épocas de entressafras agrícolas. Esses resultados podem ser potencializados com um maior beneficiamento das matérias-primas, resultando em produtos mais elaborados, com maior valor agregado. A Cooperativa COORIMBATÁ é um caso especial, pois conta com a figura do Pesquisador Cooperado, reconhecida como Tecnologia Social pela Fundação Banco do Brasil e sua Rede de Tecnologias Sociais, foi empresa incubada e hoje é empresa graduada. São filiadas à COORIMBATÁ, a Cooperativa Agropecuária Varzeagrandense (COOPERGRANDE) e a Associação dos Pequenos Produtores Rurais da Comunidade Imbê, do Município de Poconé (ASPPRUCI). A COOPERGRANDE é uma cooperativa de assentados da reforma agrária, e a ASPPRUCI é uma associação de uma comunidade quilombola. Este tipo de articulação é único no Território da Cidadania da Baixada Cuiabana e reflete os avanços possibilitados pela articulação em rede, promovidos pelo SITECS.

Em outro campo de atuação, porém com grande potencial de desenvolvimento e diferenciação, baseado na biodiversidade brasileira, está a indústria farmacêutica, especificamente na área de fitoterápicos. Assim como a indústria de higiene pessoal, perfumaria e cosméticos, a indústria farmacêutica é fortemente dependente da pesquisa, desenvolvimento e inovação (PD\&I). Pavitt (1993) analisou a relação entre pesquisa básica e o processo de aprendizagem nas empresas e concluiu que os setores industrias baseados em ciência se caracterizam pela importância e aproximação entre os seus próprios laboratórios e departamentos de PD\&I, com os da ciência pública e de seus fornecedores, sendo estas as principais fontes de conhecimento para a inovação de processos e produtos. As indústrias brasileiras do setor de higiene pessoal, perfumaria e cosméticos investiram $2 \%$ de seu faturamento 
líquido em PD\&I, no ano de 2016, percentual que vem se repetindo na última década e que coloca o setor na segunda posição do ranking nacional (ABIHPEC, 2019). Gonçalves \& Pinho (2012) analisaram os dados da Pesquisa de Inovação Tecnológica - Pintec, do setor farmacêutico para o período entre 2006 e 2008, realizado com 485 indústrias instaladas no Brasil. Os autores concluíram que, apesar de $75 \%$ das empresas desenvolverem inovações em produtos e $69 \%$ em processos, apenas $6 \%$ das inovações em produtos tinham alcance mundial. Com relação aos investimentos em PD\&I, a pesquisa indica a aplicação média de $1,4 \%$ do faturamento líquido das indústrias. Neste mesmo trabalho, os autores realizaram pesquisa de campo com as seis maiores indústrias de capital nacional e observaram que todas investiram em PD\&I, com valores que variaram de 2 a $7,5 \%$ do faturamento bruto, enquanto as empresas multinacionais instaladas no Brasil realizaram esforços inovativos locais muito limitados. Além disso, destaca-se que todas as empresas de capital nacional pesquisadas possuem parcerias de PD\&I com universidades e institutos de pesquisas brasileiros. Este resultado é semelhante ao obtido por Teixeira (2014), que analisou as 10 maiores empresas farmacêuticas de capital nacional e concluiu que o investimento médio em PD\&I por essas empresas foi de $6 \%$ de seu faturamento líquido.

Para a sobrevivência das empresas inseridas em setores que demandam fortes investimentos em PD\&I, torna-se fundamental a manutenção da competitividade a criação de alianças (Lane \& Lubatkin, 2016). Particularmente para o caso brasileiro, onde o porte das empresas e suas respectivas áreas de PD\&I ainda são pouco desenvolvidas, mais relevantes se tornam as parcerias e alianças entre as empresas, universidades e institutos de pesquisa, uma vez que a partir da Lei de Inovação (Brasil, 2004), criou-se um ambiente jurídico institucional de maior estabilidade.

A biodiversidade brasileira, particularmente na disponibilidade de derivados de origem vegetal (óleos, extratos, tinturas, etc.), possibilita uma significativa agregação de valor e apelo comercial trazido pelo tema da sustentabilidade, que resulta em um grande potencial de desenvolvimento e diferenciação para as indústrias brasileiras em ambos os setores. No setor farmacêutico, destaca-se o desenvolvimento de fitoterápicos, onde o primeiro medicamento desenvolvido com tecnologia $100 \%$ nacional, isto é, que vai desde as pesquisas básicas para identificação do princípio ativo até sua autorização para comercialização, foi um anti-inflamatório fitoterápico criado a partir da erva baleeira (Cordia verbenacea).

Ampliando o olhar para além da indústria e focando nas potencialidades de desenvolvimento de toda a cadeia produtiva da biodiversidade, $o$ Brasil também dispõe da Política Nacional de Plantas Medicinais e Fitoterápicos (Brasil, 2006), que possibilitou à Anvisa implementar uma regulamentação diferenciada e que gera valor de mercado aos fitoterápicos (Capanema \& Palmeira Filho, 2007) e da Lei 13.123 (Brasil, 2015), que procura impedir a biopirataria e possibilitar a repartição de benefícios, como marcos regulatórios que objetivam dispersar por diferentes setores e classes sociais os resultados socioeconômicos obtidos da utilização da biodiversidade brasileira.

O desenvolvimento da indústria farmacêutica brasileira foi fortemente influenciado por políticas públicas que regulamentaram o setor. Como marcos relevantes dessa influência, destacam-se: a Lei de 
Propriedade Industrial (Brasil, 1996b), que seguiu as orientações estabelecidas pela Organização Mundial do Comércio - OMC, no Acordo TRIPS (Trade - Related Aspects of Intellectual Property Rights) e estabeleceu que as patentes internacionais, em todos os setores, passavam a vigorar também no Brasil seguindo as regras e prazos estabelecidos pela OMC; a Política Nacional de Medicamentos (MS, 1998), que seguindo as diretrizes da Organização Mundial de Saúde - OMS, estabelece a relação de medicamentos essenciais, reorienta a assistência farmacêutica, estimula a produção de medicamentos e a sua regulamentação sanitária, que se efetiva com a criação da Agência Nacional de Vigilância Sanitária - ANVISA; por fim, pode-se citar a Lei do Medicamento Genérico (Brasil, 1999), que criou esse tipo de medicamento no mercado brasileiro e dispôs sobre a utilização de nomes genéricos em produtos farmacêuticos, além de outros decretos presidenciais e resoluções da ANVISA, que intensificaram a fiscalização do controle de qualidade dos medicamentos, seguindo padrões internacionais, e a regulamentação de toda cadeia farmacêutica. Capanema \& Palmeira Filho (2007) concluem que todo esse arcabouço legal proporcionou uma maior garantia à qualidade dos fármacos produzidos e comercializados no Brasil, o que forçou as indústrias brasileiras a investir em adequações tecnológicas, sejam estruturais, de processos ou de produtos. Em contraposição, Gonçalves \& Pinho (2012) mostraram resultados ambíguos para a indústria farmacêutica nacional, que, por um lado, vem tendo acúmulo de capital e apresentando uma ampliação no esforço tecnológico, por outro, continua centrada em ativos comerciais de baixo desenvolvimento tecnológico, principalmente proporcionados pelos medicamentos genéricos que são muito significativos nos portfólios da maior parte das indústrias nacionais.

Estes exemplos indicam que a correta utilização da biodiversidade brasileira, isto é, que possibilite sua utilização e manutenção, poderá desempenhar um importante papel indutor de sinergia entre arranjos produtivos locais do interior do Brasil, com pesquisas científicas que viabilizem sua utilização, e indústrias nacionais, possibilitando o desenvolvimento de cadeias produtivas completas, alicerçadas em conceitos de uma nova bioeconomia.

\section{Proposições para o desenvolvimento da cadeia produtiva da biodiversidade brasileira a partir de seus óleos vegetais}

A utilização da biodiversidade brasileira, considerando os aspectos ambientais, sociais e econômicos, poderá desempenhar um papel inovador na construção de uma nova bioeconomia mundial, que tem como grande desafio conciliar a melhoria da qualidade de vida das pessoas da base da pirâmide social com a redução dos impactos ambientais (Fukayama, 2013). Indo além dos negócios sociais propostos por Yunus (2010), e a partir da biodiversidade brasileira, podem-se criar arranjos produtivos sociais que integrem cooperativas e associações de comunidades locais, universidades e institutos de pesquisas, indústrias e instituições governamentais. Com essa perspectiva, a biodiversidade brasileira torna-se um eixo estratégico de desenvolvimento sustentável para o país. Nesse contexto, apesar do grande avanço na consolidação de políticas públicas sobre o tema da biodiversidade, ocorrido nas últimas duas décadas, ainda se fazem necessários importantes ajustes para a transversalidade do tema. 
Apesar da existência da Política Nacional da Biodiversidade, os temas da conservação e da produção são tratados separadamente, com diferentes ministérios responsáveis por cada tema, MMA e MAPA, respectivamente.

Caracterizados pela sazonalidade e dispersão territorial, os PFNM devem constituir, estrategicamente, um único arranjo produtivo a partir de suas unidades extrativistas, com ramificações posteriores para os diferentes setores industriais ou de serviços. Nesse sentido, os óleos vegetais tornam-se fortes indutores das unidades extrativistas, possibilitando que a agregação de valor de outros PFNM parta de uma estrutura produtiva já consolidada e que possa, dessa forma, aumentar a sustentabilidade econômica do empreendimento pela diversificação de produtos.

Observando o processo de expansão mundial do azeite de oliva, identificam-se as três principais frentes de ação: políticas públicas de apoio à cadeia produtiva; pesquisa de desenvolvimento tecnológico, com destaque para a mudança do processo de extração na década de 1970; marketing, com a disseminação das qualidades da dieta mediterrânea.

Para os óleos vegetais da biodiversidade, o desenvolvimento de ciência e tecnologia adequado às características dos empreendimentos se torna fundamental. Equipamentos e processos em batelada, multiuso e de pequena escala, com rendimentos compatíveis com os de escala industrial, tornam-se necessários. Exemplos da viabilidade desse tipo de tecnologia podem ser observados nas indústrias de óleos essenciais ou ainda nas indústrias processadoras de óleo de palma, que para o óleo de palmiste utilizam equipamentos em batelada e de pequena escala para o processo de desodorização.

A utilização do $\mathrm{SiBBr}$ deve ser coordenada e incentivada para o compartilhamento de conhe- cimento e tecnologias que atendam a essa cadeia produtiva.

O salto verde ("green leap"), proposto por Hart (2010), pode surgir de tecnologias cocriadas por membros do arranjo produtivo social em parceria com as comunidades locais, gerando soluções de baixo para cima com uma menor imposição tecnológica do que as de cima para baixo (Fukayama, 2013). Nesse sentido, o desenvolvimento e a reaplicação de tecnologias sociais, tais como do pesquisador cooperado, poderão contribuir na construção de relações de confiança, que são necessárias e fundamentais nesse contexto.

No campo mercadológico e de marketing, os óleos vegetais da biodiversidade já carregam um diferencial trazido pelas questões ambientais e de sustentabilidade. Duchelle et al. (2014) avaliaram os benefícios socioeconômicos da certificação da castanha-do-brasil, indicando que no Brasil, em comparação a Peru e Bolívia, é o de menor impacto, por outro lado, indicando que as situações dos países vizinhos indicam as possibilidades de desenvolvimento no Brasil. Desta forma, a criação de um selo específico para os produtos da sociobiodiversidade brasileira, que se inspire, por exemplo, no modelo proposto pelo selo ambiental alemão Blauer Engel (Blue Angel, 2017), poderá ser um importante instrumento de valorização e divulgação. A divulgação dos benefícios à saúde e as qualidades e possibilidades da culinária e gastronomia a partir desses óleos poderão ser estratégias importantes de divulgação.

\section{Agradecimentos}

Este trabalho contou com apoio da FAPESP (2014/21252-0, 2016/10636-8), do CNPq 
(406856/2013-3, 305870/2014-9, 309780/2014-4) e da CAPES (PROEX - 2952/2011). Sampaio Neto agradece a Universidade Federal de Mato Grosso e a CAPES pela bolsa de estudo através do programa pró-doutoral. Agradecimento especial as cooperativas COOPAVAM (MT), COORIMBATÁ (MT) e COPPALJ (MA) que inspiraram a realização deste trabalho.

\section{Referências}

ABIHPEC - Associação Brasileira da Indústria de Higiene Pessoal, Perfumaria e Cosméticos. Panorama do Setor de Higiene Pessoal, Perfumaria e Cosméticos - Resultados 2018, 2019. Disponível em: <https://abihpec.org.br/publicacao/panorama-do-setor-2017/>. Acesso em: jan. 2020.

ABIOVE - Associação Brasileira de Indústrias de Óleos Vegetais. Pesquisa de Capacidade Instalada da Indústria de Óleos Vegetais - 2018, 2018. Disponível em: <http:// www.abiove.org.br/site/index.php?page=estatistica\&area $=$ NCOyLTE $>$. Acesso em: fev. 2020.

AICA - Agencia de Información y Control Alimentarios. Información de Mercados Azeite. Información de Mercados Azeite, 2017. Disponível em: <https://servicio.mapama. gob.es/InformacionMercado_Aica/Inicio.aao>. Acesso em: dez. 2019.

Anderson, D. A Primer on Oils Processing Technology. In: Hui, Y. H. (Ed.). Bailey's Industrial Oil and Fat Products. New York: John Wiley \& Son, p. 10-17, 1996.

ANVISA - Agência Nacional de Vigilância Sanitária. Resolução RDC $n^{\circ}$ 270, de 22 de setembro de 2005. Regulamento técnico para óleos vegetais, gorduras vegetais e creme vegetal, 2005.

Arakaki, A. H.; Priante Filho, N.; Sampaio Neto, O. Z.; Figueiredo, J. M.; Luconi, W.; Paese, J. Sistema Integrado de Inovação Tecnológica Social: programa de incubação de empreendimentos econômicos solidários EIT-UFMT. Interações, 13(1), 59-68, 2012. doi: 10.1590/S151870122012000100006
Blue Angel. Blue Angel - The german ecolabel, 2017. Disponível em: $<$ https://www.blauer-engel.de/en/our-label-environment>. Acesso em: abr. 2019.

Brasil. Decreto $n^{\circ} 51.209$, de 18 de agosto de 1961. Aprova as novas especificações para classificação e fiscalização da exportação da "Castanha do Brasil". Brasília: DOU de 19/08/1969.

Brasil. Decreto-lei $n^{\circ}$ 79, de 19 de dezembro de 1966. Institui normas para a fixação de preços mínimos e execução das operações de financiamento e aquisição de produtos agropecuários e adota outras providências. Brasilia: DOU de 20/12/1966.

Brasil. Decreto $n^{\circ}$ 1.946, de 28 de junho de 1996. Cria o Programa Nacional de Fortalecimento da Agricultura Familiar - PRONAF, e dá outras providências. Brasília: DOU de 29/06/1996a.

Brasil. Lei $n^{\circ}$ 9.279, de 14 de maio de 1996. Regula direitos e obrigações relativos à propriedade industrial. Brasilia: DOU de 15/05/1996b.

Brasil. Lei $n^{\circ}$ 9.787, de 10 de fevereiro de 1999. Dispõe sobre a vigilância sanitária, estabelece o medicamento genérico, dispõe sobre a utilização de nomes genéricos em produtos farmacêuticos e dá outras providências. Brasilia: DOU de 11/02/1999.

Brasil. Decreto $n^{\circ} 4.339$, de 22 de agosto de 2002. Institui princípios e diretrizes para a implementação da Política Nacional da Biodiversidade. Brasília: DOU de 23/08/2002.

Brasil. Lei $n^{\circ} 10.696$ de 02 de julho de 2003. Dispõe sobre a repactuação e o alongamento de dívidas oriundas de operações de crédito rural, e dá outras providências. Brasília: DOU de 03/07/2003.

Brasil. Lei $n^{\circ}$ 10.973, de 02 de dezembro 2004. Dispõe sobre incentivos à inovação e à pesquisa científica e tecnológica no ambiente produtivo e dá outras providências. Brasilia: DOU de 03/12/2004.

Brasil. Decreto $n^{\circ}$ 5.813, de 22 de junho de 2006. Política Nacional de Plantas Medicinais e Fitoterápicos. Brasilia: DOU de 23/06/2006.

Brasil. Decreto $n^{\circ}$ 6.040, de 07 de fevereiro de 2007. Institui a Política Nacional de Desenvolvimento Sustentável 
dos Povos e Comunidades Tradicionais. Brasília: DOU de 08/02/2007.

Brasil. Lei $n^{\circ}$ 11.775, de 17 de setenbro de 2008. Institui medidas de estímulo à liquidação ou regularização de dívidas originárias de operações de crédito rural e de crédito fundiário. Brasília: DOU de 18/09/2008.

Brasil. Lei $n^{\circ}$ 11.947, de 16 de junho de 2009. Dispõe sobre o atendimento da alimentação escolar e do Programa Dinheiro Direto na Escola aos alunos da educação básica. Brasília. DOU de 17/06/2009.

Brasil. Decreto $n^{\circ} 7.775$, de 04 de julho de 2012. Regulamenta o art. 19 da Lei no 10.696, de 2/07/2003. Brasilia. DOU de 05/07/2012a.

Brasil. Lei $n^{\circ}$ 12.651, de 25 de maio de 2012. Dispõe sobre a proteção da vegetação nativa. Brasília. DOU de 26/05/2012b.

Brasil. Lei $n^{\circ} 13.123$, de 20 de maio de 2015. Dispõe sobre o acesso ao patrimônio genético, sobre a proteção e o acesso ao conhecimento tradicional associado e sobre a repartição de benefícios para conservação e uso sustentável da biodiversidade. Brasília. DOU de 21/05/2015.

Capanema, L. X. D. L.; Palmeira Filho, P. L. Indústria farmacêutica brasileira: reflexões sobre sua estrutura e potencial de investimentos. In: Torres Filho, E. T.; Puga, F. P. (Eds.). Perspectivas do investimento 2007/2010. Rio de Janeiro, RJ: BNDES, p. 163-206, 2007. Disponível em: http://www.bndespar.com.br/SiteBNDES/export/ sites/default/bndes_pt/Galerias/Arquivos/conhecimento/ liv_perspectivas/06.pdf

Carrazza, L. R.; Silva, M. L.; Ávila, J. C. C. Manual Tecnológico de Aproveitamento Integral do Fruto do Babaçu. Brasília-DF: Instituto Sociedade, População e Natureza (ISPN), 2012. Disponível em: <http://www.ispn.org.br/ arquivos/Mont_babacu006.pdf $>$. Acesso em: nov de 2019.

CIAPO - Câmara Interministerial de Agroecologia e Produção Orgânica. Plano Nacional de Agroecologia e Produção Orgânica - PLANAPO. In: MDS (Ed.). Statewide Agricultural Land Use Baseline 2015. Brasília, DF: CIAPO, 2013. doi: 10.1017/CBO9781107415324.004

Davenport, R. B.; May, P. H.; Nogueira, P.; Nunes, P. C.
A policy mix to prevent a non-commons tragedy for collective forest reserves in agrarian settlements in northwest Mato Grosso. Revista de Economia Contemporânea, 20(3), 405-429, 2016. doi: 10.1590/198055272032

Dijkstra, A. J.; Segers, J. C. Production and refining of oils and fats. In: Gunstone, F. D.; Harwood, J. L.; Dijkstra, A. J. (Eds.). The Lipid Hand Book with CD (3rd ed.). Boca Raton: CRC Press, p. 143-262, 2007.

Duchelle, A. E.; Kainer, K. A.; Wadt, L. H. O. Is Certification Associated with Better Forest Management and Socioeconomic Benefits? A Comparative Analysis of Three Certification Schemes Applied to Brazil Nuts in Western Amazonia. Society and Natural Resources, 27(2), 121-139, 2014. doi: 10.1080/08941920.2013.840022

Escobal, J.; Aldana, U. Are nontimber forest products the antidote to rainforest degradation? Brazil nut extraction in Madre De Dios, Peru. World Development, 31(11), 1873-1887, 2003. doi: 10.1016/j.worlddev.2003.08.001

Fukayama, M. Inovação e Tecnologia nos Negócios com Impacto Social. In: Bark, E.; Izzo, D.; Torres, H. G.; Aguiar, L. (Eds.). Negócios com impacto social no Brasil. São Paulo, SP: Peirópolis, p. 170-186, 2013.

Gonçalves, M. C. B.; Pinho, M. Estratégias tecnológicas em transformação: um estudo da indústria farmacêutica brasileira. Gestão Da Produção, 19(2), 405-418, 2012. doi: 10.1590/S0104-530X2012000200013

Gunstone, F. D.; Harwood, J. L. Occurrence and Characterisation of Oils and Fats. In: Gunstone, F. D.; Harwood, J. L.; Dijkstra, A. J. (Eds.). The lipid handbook with CD-ROM (3rd ed). CRC Press. p. 37-142, 2007.

Hart, S. L. Capitalism at the crossroads: Next generation business strategies for a post-crisis world $\left(3^{\mathrm{a}}\right)$. Upper Saddle River, NJ: Wharton School Pub., 2010.

Harwood, L. J.; Aparicio, R. Handbook of olive oil: analyses and properties. Gaithersburg, Maryland: Aspen Publishers. 2000 .

IBGE - Instituto Brasileiro de Geografia Estatísitica. Censo Agropecuário 2006-Brasil, Grandes Regiões e Unidades da Federação. Rio de Janeiro, RJ: IBGE. 2009. Disponível em: $<$ http://biblioteca.ibge.gov.br/visualizacao/periodicos/51/ 
agro_2006.pdf>. Acesso em: dez. 2019.

IBGE - Instituto Brasileiro de Geografia e Estatítica. Sistema IBGE de Recuperação Automática - SIDRA, 2017. Disponível em: <https://sidra.ibge.gov.br/tabela/289>. Acesso em: nov. 2019.

IOC - International Olive Council. Mission \& basic text, 2016. Disponível em: <http://www.internationaloliveoil. org/estaticos/view/100-mission-statement $>$. Acesso em: fev. 2020 .

Karnofsky, G. The Mechanics of Solvent Extraction. JAOCS, Journal of the American Oil Chemists 'Society, 20(10), 570-574, 1949.

Kumar, S. P. J.; Prasad, S. R.; Banerjee, R.; Agarwal, D. K.; Kulkarni, K. S.; Ramesh, K. V. Green solvents and technologies for oil extraction from oilseeds. Chemistry Central Journal, 11(1), 9-15, 2017. doi: 10.1186/s13065-017-0238-8

Lane, P. J.; Lubatkin, M. Relative Absorptive Capacity and Interorganizational Learning. Strategic Management Journal, 19, 461-477, 2016.

Machado, G. C.; Chaves, J. B. P.; Antoniassi, R. Composição em ácidos graxos e caracterização física e química de óleos hidrogenados de coco babaçu. Revista Ceres, 53, 463-470, 2006.

MAPA - Ministério da Agricultura Pecuária e do Abastecimento. Instrução Normativa $n^{\circ} 01$, de 30 de janeiro de 2012. Regulamento técnico do azeite de oliva e do óleo de bagaço de oliva, 2012.

MCTIC - Ministério da Ciência Tecnologia Inovações e Comunicações. Sistema de Informação sobre a biodiversidade brasileira - SiBBr, 2017. Disponível em: <http:// www.sibbr.gov.br/>. Acesso em: jun. 2019.

MDA - Ministério do Desenvolvimento Agrário; MDS Ministério do Desenvolvimento Social; MMA - Ministério do Meio Ambiente. Portaria interministerial MDA, MDSe $M M A n^{\circ} 239$, de 21 de julho de 2009. Estabelece orientações para a implementação do Plano Nacional de Promoção das Cadeias de Produtos da Sociobiodiversidade, e dá outras providências. Brasília, DOU de 22/07/2009.

MDIC - Ministério da Indústria Comércio Exterior e Serviços. COMEXSTAT, 2018. Disponível em: <http://comexstat. mdic.gov.br/pt/home >. Acesso em out. 2019.

MMA - Ministério do Meio Ambiente. Apoio a consolidação de cadeias de valor de óleos vegetais relevantes para povos e comunidades tradicionais da Amazônia. Etapa 1: Diagnóstico das principais cadeias de óleos vegetais da Amazônia. Brasília-DF, 2006.

MMA - Ministério do Meio Ambiente. Banco de dados de compradores de produtos da sociobiodiversidade, 2016. Dispónível em: http://www.mma.gov.br/desenvolvimento-rural/sociobiodiversidade/banco-de-dados/item/10518. Acesso em: nov. 2019.

MS - Ministério da Saúde. Portaria n ${ }^{\circ}$ 3.916, de 30de outubro de 1998. Política Nacional de Medicamentos. Brasilia. DOU de 31/10/1998.

Navarro, A. L. Las cooperativas en la cadena del aceite de oliva: estrategias y perspectivas. REVESCO. Revista de Estudios Cooperativos, 72, 151-173, 2000a.

Navarro, A. L. Tendencias de futuro en la producción y la industria del aceite de oliva (1). Distribución y Consumo, 10(54), 53-96, 2000b. Disponível em: http://www.magrama.gob.es/ministerio/pags/biblioteca/revistas/pdf_DYC/ DYC_2000_54_53_81.pdf

Paiva, P. M.; Guedes, M. C.; Funi, C. Brazil nut conservation through shifting cultivation. Forest Ecology and Management, 261(3), 508-514, 2011. doi: 10.1016/j. foreco.2010.11.001

Pavitt, K. What do firms learn from basic research? In: Foray, D.; Freeman, C. (Eds.). Technology and the Wealth of Nations: The Dynamics of Constructed Advantage. New York: St. Martin’s Press, p. 29-40, 1993.

Pinheiro, C. U. B.; Frazao, J. M. F. Integral Processing of Babassu Palm (Orbignya-Phalerata, Arecaceae) Fruits Village Level Production in Maranhao, Brazil. Economic Botany, 49(1), 31-39, 1995. doi:10.1007/BF02862274

Roma, J. C.; Saccaro Júnior, N. L.; Mation, L. F.; Paulsen, S. S. A Economia de Ecossistemas e da Biodiversidade no Brasil (TEEB-Brasil). Relatório da Fase 1 - Análise de Lacunas. Brasília, DF, 2012. Disponível em: $<$ https://www. ipea.gov.br/portal/images/stories/PDFs/TDs/td_1912.pdf $>$. Acesso em: jan. 2019. 
Saccaro Jr, N. L. Desafios da bioprospecção no Brasil (Textos para Discussão n ${ }^{\circ}$ 1569). Brasília, DF, 2011. Disponível em: <http://www.ipea.gov.br/portal/images/stories/PDFs/ TDs/td_1569.pdf $>$. Acesso em: jan. 2020.

Salomão, R. de P. Densidade, estrutura e distribuição espacial de castanheira do Brasil (Bertholletia excelsa $\mathrm{H}$. \& B.) em dois platôs de floresta ombrófila densa na Amazônia setentrional brasileira. Boletim Do Museu Paraense Emílio Goeldi, 4(1), 11-25, 2009. Disponível em: http:// scielo.iec.pa.gov.br/scielo.php?script=sci_arttext\&amp;pi81142009000100002\&amp;lng=en\&amp;nrm=isso\&amp;tlng $=\mathrm{pt}$

Sampaio, K. A. Desacidificação por via física de óleo de palma: efeito da composição do óleo, das perdas de compostos nutracêuticos e cinéticas de degradação. Campinas, Tese (Doutorado em Engenharia de Alimentos) - Unicamp, 2011. Disponível em: http://repositorio.unicamp.br/jspui/ handle/REPOSIP/255200

Sampaio Neto, O. Z.; Batista, E. A. C.; Meirelles, A. J. A. The employment of ethanol as solvent to extract Brazil nut oil. The Journal of Cleaner Production, 180, 866-875, 2018. doi: 10.1016/j.jclepro.2018.01.149

Shanley, P.; Serra Silva, M.; Melo, T.; Carmenta, R.; Nasi, R. From conflict of use to multiple use: Forest management innovations by small holders in Amazonian logging frontiers. Forest Ecology and Management, 268, 70-80, 2012. doi: 10.1016/j.foreco.2011.05.041

Shiki, S. Política agrária e conservação da biodiversidade no Brasil. Estudos Sociedade e Agricultura, 18(2), 288-316, 2010. Disponível em: http://socialsciences.scielo.org/pdf/s_esaa/v5nse/scs_a04.pdf0004\&nrm=iso

Sukhdev, P.; Wittmer, H.; Schroter-Sclaack, C.; Nesshover, C.; Bishop, J.; Brink, P. Neville, A. TEEB (2010) A Economia dos Ecossistemas e da Biodiversidade: Integrando a economia da natureza. Uma síntese da aboragem, conclusões e recomendações do TEEB. The Economics of Ecosystems and Biodiversity. Nairobi, 2010.

Teixeira, A. A Indústria Farmacêutica no Brasil: um estudo do impacto socioeconômico dos medicamentos genéricos. Araraquara, Monografia (Economia) - UNESP, 2014. Disponível em: https://repositorio.unesp.br/bitstream/han- dle/11449/124346/000830044.pdf;sequence $=1$

Thomas, E.; Valdivia, J.; Caicedo, C. A.; Quaedvlieg, J.; Wadt, L. H. O.; Corvera, R. NTFP harvesters as citizen scientists: Validating traditional and crowdsourced knowledge on seed production of Brazil nut trees in the Peruvian Amazon. PLoS ONE, 12(8), 1-20, 2017. doi: 10.1371/ journal.pone. 0183743

Tonini, H. Amostragem para a estimativa de produção de sementes de castanheira-do-brasil em floresta nativa. Pesquisa Agropecuaria Brasileira, 48(5), 519-527, 2013. doi: 10.1590/S0100-204X2013000500008

Tonini, H.; Pedrozo, C. Â. Variações anuais na produção de frutos e sementes de Castanheira-do-Brasil (Bertholletia excelsa Bonpl., Lecythidaceae) em florestas nativas de Roraima. Revista Árvore, 38(1), 133-144, 2014. doi: 10.1590/ S0100-67622014000100013

USDA - United States Department of Agriculture. February 2020 Oilseeds: Worl Market and Trade. Disponível em: $<$ https://apps.fas.usda.gov/psdonline/circulars/oilseeds. pdf $>$. Acesso em fev. 2020.

Vosti, S. A.; Braz, E. M.; Carpentier, C. L.; D’Oliveira, M. V. N.; Witcover, J. Rights to frest products, deforestation and smallholder income: Evidence from the Western Brazilian Amazon. World Development, 31(11), 1889-1901, 2003. doi: 10.1016/j.worlddev.2003.06.001

Wadt, L. H. O.; Kainer, K. A.; Gomes-Silva, D. A. P. Population structure and nut yield of a Bertholletia excelsa stand in Southwestern Amazonia. Forest Ecology and Management, 211(3), 371-384, 2005. doi: 10.1016/j.foreco.2005.02.061

Wadt, L. H. O.; Faustino, C. L.; Staudhammer, C. L.; Kainer, K. A.; Evangelista, J. S. Primary and secondary dispersal of Bertholletia excelsa: Implications for sustainable harvests. Forest Ecology and Management, 415-416, 98-105, 2018. doi: 10.1016/j.foreco.2018.02.014

Wakelyn, P. J.; Wan, P. J.; Akoh, C. C. Solvent extraction to obtain edible oil products. In: Akoh, C. C. (Ed.). Handbook of functional lipids. Boca Raton: CRC Press. p. 89-131, 2006.

Yang, J. Brazil nuts and associated health benefits: A review. LWT - Food Science and Technology, 42(10), 1573-1580, 
2009. doi: 10.1016/j.lwt.2009.05.019

Yunus, M. Criando um negócio social: como iniciativas economicamente viáveis podem solucionar os grandes problemas da sociedade (1st ed.). Rio de Janeiro, RJ: Elsevier, 2010.
Zampounis, V. Olive Oil in World Market. In: Boskou, D. (Ed.). Olive Oil: Chemistry and Technology. Champaign, IL: AOCS Press., p. 21-39, 2006. 